\title{
Spatial Energy Planning: A Review
}

\author{
Juan Carlos Osorio-Aravena ${ }^{1,2, *(\mathbb{D}}$, Marina Frolova ${ }^{3}$, Julio Terrados-Cepeda ${ }^{2}$ (i) and \\ Emilio Muñoz-Cerón 2 (D) \\ 1 Laboratorio Eco-Climático, Universidad Austral de Chile, Campus Patagonia, Coyhaique 5950000, Chile \\ 2 Engineering Projects Area, Department of Graphic Engineering, Design and Projects, University of Jaén, \\ 23071 Jaén, Spain; jcepeda@ujaen.es (J.T.-C.); emunoz@ujaen.es (E.M.-C.) \\ 3 Department of Regional and Physical Geography, Institute for Regional Development, \\ University of Granada, 18071 Granada, Spain; mfrolova@ugr.es \\ * Correspondence: juan.osorio@uach.cl
}

Received: 5 August 2020; Accepted: 29 September 2020; Published: 15 October 2020

\begin{abstract}
Despite the fact that some renewable energy (RE) technologies are already techno-economically viable, the high spatial dilution nature of their sources, together with aspects beyond the techno-economic ones (such as environmental, social, cultural, and other aspects), can become strong constraints and barriers when it comes to their integration into electric systems. Therefore, with the objective of determining whether studies on spatial energy planning (SEP) are addressing these issues, a systematic review has been carried out to address whether SEP studies are considering aspects beyond the techno-economic ones when integrating RE technologies and, if they are being considered, how they are addressed in their analyses and what criteria, factors, and indicators of the aspects that are employed. Apart from the revelation that the concept of SEP has been included within high-quality scientific literature for less than ten years, SEP seems to be an unexploited tool with the potential to provide significant insight into a planning process that could prevent conflicts when integrating RE technologies into electric systems. This would be useful for decision-makers and for accelerating a sustainable energy transition.
\end{abstract}

Keywords: renewable energy; energy planning; planning tool; sustainability; environmental; social; decision-makers; sustainable energy transition

\section{Introduction}

Renewable electricity technologies are vital elements in achieving global climate targets [1-3]. However, the transition from the current fossil-fuel-based energy system to a renewable energy (RE) system needs to be accelerated [4]. Although various renewable electricity technologies are already technically feasible and economically viable $[5,6]$, the spatial low-density of some renewable sources with a large land use footprint, together with their environmental, social, and landscape impacts, have become strong constraints and barriers when it comes to their integration into energy systems [7-10]. These barriers are related not only to the usual "developer" vs. "local population" syndrome, but also to the conflict between energy policy and land use planning processes [11]. Therefore, when integrating RE technologies into energy systems, synergies and trade-offs with other sustainability concerns should be considered, such as water and land use, landscape impacts, and socio-economic aspects [12-15].

However, most energy planning approaches are centralized and mainly based on energy modeling tools with a focus on techno-economic aspects [16]. On the one hand, the environmental and landscape impacts are typically considered when an RE project requires approval to be built. Their assessment criteria are directly related to the specific country's environmental, landscape, and land-use planning regulations, which vary from country to country [10]. Moreover, although an individual RE project 
may have support from the government, in many cases, it will face social opposition [4]. On the other hand, the amount of greenhouse gas emissions is the most common environmental factor and indicator that energy system models have been used. At the residential level, the HOMER simulation tool has been used to carry out a techno-economic-environmental analysis within the context of the sustainable development goal 7 [17]. The HOMER software tool has also been used for a feasibility analysis of the resilient of power supply systems' configuration from the techno-economic and life-cycle environmental emission perspective [18]. However, energy system models can be improved in order to be coupled with integrated assessment models for a more comprehensive and multi-disciplinary understanding of defossilization pathways for the benefit of policymakers, stakeholders, and communities [19-21].

Furthermore, models on decentralized energy systems also lack insight related to social aspects and spatial resolutions [22]. Actually, understanding of the energy, social, and spatial dynamics at the local level has become an important issue in the literature on RE development [10,23-26]. Oudes and Stremke [27] have proposed a methodological framework for assessing the spatio-technological feasibility of energy transition targets at the local and regional scale. They based their methodology on the concept of Spatial Transition Analysis, which is spatially explicit and evidence-based, with regard to RE technologies, and inclusive of stakeholder preferences and values. At the same time, several authors [28-38] have employed complex trade-off analyses for RE development and multi-criteria decision analyses, as well as a variety of tools and theoretical approaches at different levels. In a similar way, the spatial energy planning (SEP) concept has recently emerged in the scientific literature; however, is this concept being used as a tool that could help to overcome challenges beyond the techno-economic ones when integrating RE technologies into electric systems?

Therefore, the principal aim of this work was to reveal whether studies that used the SEP concept addressed issues related to aspects beyond techno-economic ones, in order to prevent barriers and conflicts that RE large-scale projects could face in their integration into electric systems. In this sense, first, an explanation of the emergence of this concept, as well as the framework in which it is used, was provided. Then, a systematic review of SEP presented in high-quality scientific literature was conducted. Based on this, apart from revealing that the SEP concept has existed for less than a decade in the literature, we found that SEP seems to be an unexploited tool. It has the potential to prevent barriers in the planning process for integrating RE technologies at different levels and scales. Some SEP approaches consider aspects beyond the techno-economic ones, and could be useful for strategic policies, planners, investors, and decision-makers. They could also provide benefits for communities and for accelerating the sustainable energy transition.

This paper is structured as follows. Section 2 provides a brief history on the emergence of the SEP concept and explains the framework within which it is used. Section 3 describes the process that was carried out throughout the systematic literature review. The results of this, a description of the evolution and tendencies of the SEP concept, and the articles that considered aspects beyond the techno-economic ones are presented in Section 4. In this section, the criteria, factors, and indicators related to aspects beyond the techno-economic ones are also presented. Section 5 provides an interpretation and discussion of the results, as well as recommendations for future research in the field. Lastly, conclusions are presented in Section 6.

\section{On the Emergence of the SEP Concept and the Framework in Which It Is Used}

Historically, the integration processes between space and energy planning have mainly been related to the urban environment. According to De Pascali and Bagaini [39], from the first studies that integrated urban planning and energy planning in the 1970s to the current concerns of shared sustainability and decentralized energy system solutions, they have been understood as a way to promote local development. The integration of energy variables in urban planning involved intense theoretical elaboration until the early 1990s [40-46]. The result of this was a systemic framework of the relationship between city physical-functional organization and energy and planning, which highlighted 
the importance of including energy strategies in spatial planning [39]. However, this was still far from finding an implementation [39].

During the 1970s, in parallel to the studies that started the integration of urban structures and energy planning, the integrated energy planning (IEP) concept was proposed by the International Energy Agency-along with several states-as a response to the oil crisis, in order to decrease the dependence on foreign oil and increase the energy diversity [47]. During that decade, energy planning efforts were energy models aimed at exploring the established relationships between energy and economy in the energy sector [48]. Based on this, most of the IEP methodologies were mainly applied from an economic perspective and at the national level [47]. In the 1980s, growing environmental concern slightly adapted the previous decision framework [49]. Then, the need to incorporate environmental and social aspects in energy planning occasioned the increasing use of multi-criteria approaches [48].

Under the frame of multi-criteria decision-making methods, the sustainable energy planning concept started to appear in the scientific literature during the 2000s [48] and it has received an increasing amount of interest in the last five years. However, this concept has mainly been associated with multi-criteria analysis methods and modeling and theoretical approaches [33-38,50-57] principally focused on long-term energy scenarios at the national level, in which planning and the energy policies are still unintegrated with spatial planning.

According to Cormio et al. [58], the global growing concern on environmental protection and sustainable development, along with the liberalization of the energy market in several countries, led to an increase in the interest in IEP at the sub-national level. In this regard, Mirakyan and De Guio [47] presented a generic IEP procedure for cities and territories in the early 2010s, in which the planning activities were divided into four main phases (I: preparation and orientation II: model design and detailed analysis, III: prioritization and decision, and IV: implementation and monitoring) and the implemented methods and software resources used until that time were allocated in the appropriate phase. Therefore, methods and models that quantitatively analyze the potential integration of RE technologies into energy systems are included in planning phase II, and the consideration of qualitative aspects and their eventual interaction with the spatial structures are involved in planning phase III. However, the spatial structures are not directly analyzed in the IEP procedure.

Considering the importance of re-thinking the role of spatial planning and energy planning as a strategic tool, due to its potential influence on urban design, infrastructures, mobility, land use, private property rights, the water supply, food security, environmental protection, public health, local development, resilience, and sustainability, among others, in the last decade, an Austrian research group has conceptualized the integrated spatial and energy planning (ISEP) concept [59]. The ISEP concept is defined as "the part of spatial planning that deals with the spatial dimensions of energy consumption and energy supply" [60]. Based on the interrelation between spatial structures, the energy demand, and the energy supply [61], a combination of models and methods used in both phase II and phase III of the IEP procedure can be implemented as strategy tools. Within this framework, the SEP concept has emerged during the last decade in the scientific literature.

Due to the crucial role that RE technology will play in accelerating the sustainable energy transition, we focused the analysis on the energy supply dimension of the ISEP concept.

\section{Methodology}

In this work, a systematic review of SEP, considering it as a tool to plan and design the integration of RE projects into electric systems, was conducted. The review process solely used high-quality scientific literature for the purpose of determining whether studies on SEP considered aspects beyond the techno-economic ones (such as environmental, socio-economic, social, cultural, and other aspects) when integrating RE technologies into an electric system and, if they are being considered, how they are addressed in their analyses and which criteria, factors, and indicators of the aspects are employed.

To ensure the quality of the studies, the search used Web of Science, Scopus, and ScienceDirect databases. In addition, with the aim of obtaining studies that used the SEP concept, "spatial energy 
planning"-anywhere in a document-was used as the search equation. This was used because keywords within quotation marks show documents that exactly contain those words in that order as a search result. This search was performed on 2 March 2020, so any article available in the databases used after this date was not included.

In addition to deleting duplicated studies, as one of the eligibility criteria, only journal articles were selected. Then, studies that did not really use the SEP concept in the analysis and/or as a tool were also excluded. This was conducted because some articles can contain the keywords within quotation marks, but, for instance, only in the reference list.

After the selection of articles, first, data and information were collected to describe the evolution and tendency of the SEP concept in the scientific literature, namely, the year of publication, journals of publication, type of energy system involved (electric and thermal), continent where the study was performed, level of application of the study (e.g., national, sub-national, etc.), type of RE technologies involved, and aspects analyzed in general terms (e.g., technical, techno-economic, social, environmental, and other aspects).

In a second step, the focus of the analysis was placed on articles applied to an electric energy system, as those studies involved aspects beyond the techno-economic ones. In addition to identifying those aspects, each article was described in terms of how those aspects were addressed in the study.

Finally, as a third step, criteria and factors involved in aspects beyond the techno-economic ones were identified and presented.

All of this has been considered in order to understand whether the SEP concept is helping or could help to overcome barriers beyond techno-economic aspects that have emerged in the integration of renewable electricity technologies around the world at different levels.

\section{Results}

A summary of the article selection process is illustrated in Figure 1. After searching in the Web of Science, Scopus, and ScienceDirect databases, 6 of the 26 results were removed due to duplication. Then, eight studies were excluded because they were outside of the eligibility criteria: two of them because they were not articles, and six of them because they did not really use the SEP concept in the analysis and/or as a tool. Specifically, in one of them, the SEP concept was only cited from another study, and in five of them, the SEP concept was included in the reference list.

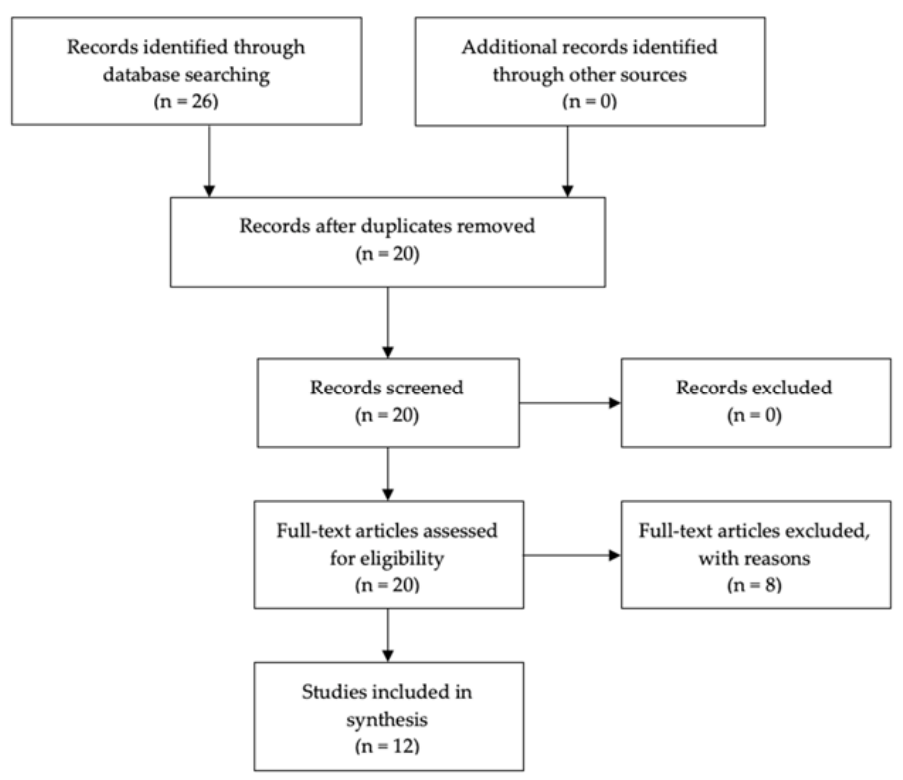

Figure 1. Flow diagram of the article selection process based on Preferred Reporting Items for Systematic Reviews and Meta-Analyses (PRISMA) guidelines [62]. 
Table 1 sets out the articles selected for analysis. As can be observed in this table, the SEP concept has been included in high-quality scientific literature for less than a decade, and 2020 is the year when the most articles have been published. The articles have been published in a variety of journals, most of which have been technical ones. More than $80 \%$ of the works were performed in Europe, and $75 \%$ of the studies were applied at the sub-national level.

Table 1. Articles selected that include the spatial energy planning (SEP) concept, with their corresponding reference, year and journal of publication, and continent and level of applications.

\begin{tabular}{|c|c|c|c|c|}
\hline Author(s) & $\begin{array}{c}\text { Year of } \\
\text { Publication }\end{array}$ & Journal & Continent & Level \\
\hline Reiter [63] & 2013 & Euroheat and Power & Europe & Sub-national \\
\hline Shubert [64] & 2014 & $\begin{array}{c}\text { Journal of Urban } \\
\text { Technology }\end{array}$ & Europe & Sub-national \\
\hline $\begin{array}{l}\text { Thygesen and } \\
\text { Agarwal [65] }\end{array}$ & 2014 & $\begin{array}{c}\text { Renewable and } \\
\text { Sustainable Energy } \\
\text { Reviews }\end{array}$ & Europe & National \\
\hline Scognamiglio [66] & 2016 & $\begin{array}{c}\text { Renewable and } \\
\text { Sustainable Energy } \\
\text { Reviews }\end{array}$ & Europe & Sub-national \\
\hline Choi et al. [67] & 2016 & $\begin{array}{l}\text { Chemical Engineering } \\
\text { Research and Design }\end{array}$ & Asia & National \\
\hline Mostegl et al. [68] & 2017 & $\begin{array}{l}\text { Landscape and } \\
\text { Urban Planning }\end{array}$ & Europe & Sub-national \\
\hline Garegnani et al. [69] & 2018 & Applied Energy & Europe & Sub-national \\
\hline Böttcher et al. [70] & 2019 & Renewable Energy & Europe & Sub-national \\
\hline Epting et al. [71] & $2020^{1}$ & Renewable Energy & Europe & Sub-national \\
\hline Boamah [72] & $2020^{1}$ & $\begin{array}{l}\text { Energy Research \& } \\
\text { Social Science }\end{array}$ & Africa & Sub-national \\
\hline Lukač et al. [73] & $2020^{1}$ & Applied Energy & $\begin{array}{c}\text { Europe and North } \\
\text { America }\end{array}$ & Sub-national \\
\hline Gusatu et al. [74] & $2020^{1}$ & $\begin{array}{l}\text { International Journal of } \\
\text { Geo-information }\end{array}$ & Europe & Transnational \\
\hline
\end{tabular}

In addition, other data and information from the selected articles were extracted, in order to describe the evolution and tendency of the SEP concept in the scientific literature. This is presented in Section 4.1. Section 4.2 describes how the studies on the SEP concept that included aspects beyond the techno-economic ones addressed their analyses. Moreover, in Section 4.3, criteria, factors, and indicators identified from those aspects are presented.

\subsection{Evolution and Tendency of the SEP Studies in the Scientific Literature}

The first SEP article [63] was published in 2013 and was applied to a thermal energy system. From 2013 to 2019, an average of 1.14 articles per year were published, adding up to a total of eight; five of them were on electric systems [65-69]. So far, four articles have been published this year (up to 2 March); three of them are on electric systems [72-74]. Therefore, it was revealed that the number of SEP articles has recently increased, with the tendency mainly being analyses related to electric energy systems.

On the other hand, all of the studies that have applied thermal energy systems [63,64,70,71] have been performed at the sub-national level, specifically, at the urban level. Of the eight studies that have applied electric energy systems, one [74] was conducted at the transnational level, two $[65,67]$ at the national level, and five $[66,68,69,72,73]$ at the sub-national level—in the countryside and/or urban places. Therefore, the SEP articles show a tendency to include studies conducted at the local level.

In terms of the aspects analyzed by the SEP articles, all of those on thermal systems were purely technical. In contrast, half of the articles on electric systems considered aspects beyond the technical 
or techno-economic ones. Thygesen and Agarwal [65] published the first article using the SEP concept to address a number of aspects beyond the techno-economic ones in the analysis, in 2014. Then, Scognamiglio [66], Mostegl et al. [68], and Boamah [72] published studies that discussed those kinds of aspects, in 2016, 2017, and 2020, respectively.

Figure 2 shows the RE technologies involved in the articles that consider electric energy systems. As can be observed in Figure 2, solar photovoltaic (PV) has been the most frequently considered technology in the SEP concept, being present in almost half of the studies, followed by wind onshore (in $27 \%$ of the studies), wind offshore, biopower, and hydropower technologies (each of them in $9 \%$ of the studies). However, the SEP analysis on wind offshore technology [74] only involved technical aspects, and the SEP study on hydropower [69] discussed techno-economic aspects. Therefore, this evidence shows that solar PV, wind onshore, and biopower are the technologies that have been analyzed, considering aspects beyond the techno-economic ones, in terms of the SEP concept.

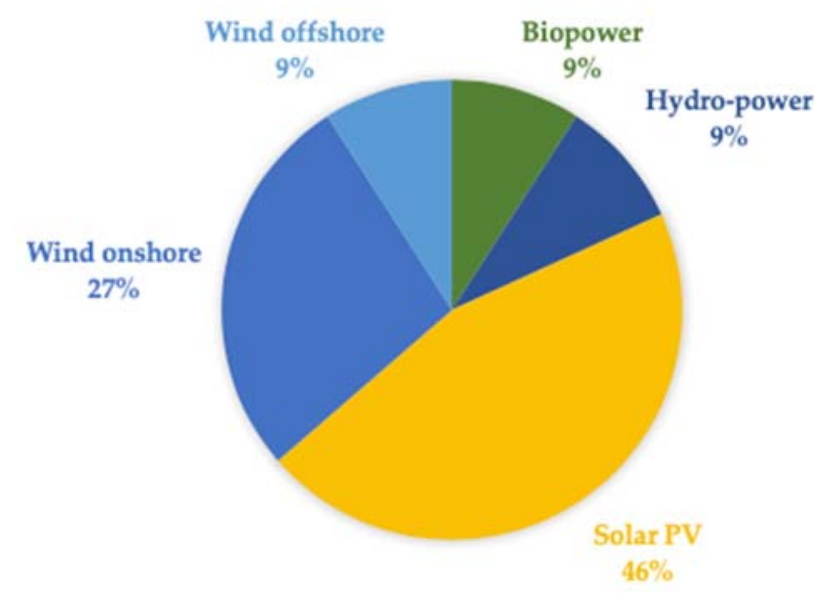

Figure 2. Share of renewable energy (RE) technologies involved in the SEP articles considering electric systems.

Therefore, the focus of the rest of this paper will be on those articles on SEP that considered electric energy systems and that contemplated aspects beyond the techno-economic ones, since they are directly aligned with the purpose of this study.

\subsection{Articles on SEP That Contemplated Aspects beyond the Techno-Economic Ones}

Four articles $[65,66,68,72]$ that addressed aspects beyond the techno-economic ones in terms of the SEP concept to integrate renewable electricity technologies were found. Descriptions of how each of these studies on the SEP concept addressed those kinds of aspects in their analysis will now be presented.

Thygesen and Agarwal [65] identified and discussed key criteria for promoting the environmentally acceptable wind planning. This was carried out through a comparison of the planning systems for wind power in Norway and Scotland. Based on a review of the impact assessment procedures in the literature, they found four key criteria for promoting sustainable wind energy planning: (i) clear and integrated political priorities; (ii) stakeholder involvement; (iii) strategic environmental assessment (SEA); and (iv) stringent permission and assessment requirements. They also found four political characteristics related to critical institutional conditions that effectively promote sustainable energy production: (a) coordinated energy policy institutions; (b) legitimate planning procedures; (c) that SEAs are followed in the decision-making process; and (d) statutory planning regulations. The authors argued that coordinated institutions, contributive stakeholder participation, and clear political priorities are crucial for addressing constraints of other environmental concerns that may not be included in SEAs related to wind power planning. 
Scognamiglio [66] carried out a critical review of the design and assessment of photovoltaic landscapes for a new trans-disciplinary design vision. This author investigated the PV landscapes in terms of patterns, in order to evaluate them, basing their analysis on technological, economic, environmental, social, and political aspects. For each aspect, quantitative and qualitative indicators were assigned (refer to Table 2). The quantitative evaluation was addressed in terms of the land use energy intensity and the qualitative one was addressed in terms of perception esthetics. The author of this work also proposed a quantitative approach focusing on land use to estimate the life cycle of the energy generation from PV landscapes. Scognamiglio [66] argued that new PV landscape patterns would allow for a better ecological performance of this technology, and also presented research questions related to the quantitative assessment of the beneficial ecological impacts that would be generated by PV patterns under a new design vision.

Mostegl et al. [68] discussed the necessities and preconditions for an integrated energy planning process using a case study in Bavaria, Germany. The main goal of this work was to identify how a community can deal with the energy transition challenges and how those challenges can be considered in planning processes. The authors recommended several improvements to the public participation processes based on a questionnaire and a visual choice experiment that they carried out in the local community. The experiment included a choice projecting tailor-made visualization of RE sources in the local landscape. They found that the questionnaire and the visual choice experiment (which involved the potential location of wind onshore and ground-mounted PV systems) both provided significant insights into the preference and acceptance of RE project locations. The authors also argued that the visual choice experiment and questionnaire revealed preferences related to the promotion of RE solutions, possible household savings, and investment models. The authors highlighted the potential of the SEP approach with public participation for avoiding social conflict in the integration of RE technologies into the electric system at the local level.

Boamah [72] discussed the desirability and debatability of decentralized solar photovoltaic systems in the context of the African continent. This work was carried out through the analysis of four idiographic cases in South Africa, Ghana, Namibia, and Kenya. The author pointed out that energy justice for all, via the massive promotion of decentralized solar electrification, is not guaranteed. They argued this as follows (p. 1): "due to contested notions of entitlements to and use of grid-based and off-grid electricity, relative spatial advantages or disadvantages, practical constraints linked to the pursuit of low-carbon energy solutions - particularly in situations where people/governments do not feel (morally) obliged to make commitments to climate change mitigation, and monopolistic tendencies of electricity distributors/suppliers. Furthermore, many electricity users in Africa lack the technical know-how and financial resources required for efficient self-organization of decentralized solar PV electrification". The author finalized the analysis by revealing that the limited commitment to low-carbon energy solutions in those countries has facilitated business models based on both the most distributed energy source (solar) and the most scalable technology (PV). These are not properly considered social aspects of the African context and have provoked an unjust electrification process with a negative economic impact on the local population.

In general terms, environmental, political, and social aspects are the main aspects that articles using the SEP concept have contemplated in their analyses. However, three of the four studies were performed to identify criteria, factors, or indicators from previous energy planning processes and existing RE systems. Only one article used the SEP concept as a strategy tool for an energy planning process.

\subsection{Criteria, Factors, and Indicators Involved in Aspects beyond the Techno-Economic Ones}

Table 2 presents the criteria, factors, and indicators related to the main aspects, beyond the techno-economic ones, that were found in the articles reviewed in depth. As can be observed in this table, there are quantitative and qualitative criteria, factors, and indicators. However, more than half of them do not have a unit. Despite this, some could be assigned a type of unit to make them measurable. 
Table 2. Criteria, factors, and indicators associated with the main aspects beyond the techno-economic ones found in articles on the SEP concept.

\begin{tabular}{|c|c|c|}
\hline Aspect and References & Criteria, Factors, and Indicators & Unit \\
\hline \multicolumn{3}{|l|}{ Environmental } \\
\hline [65] & Strategic environmental assessment & n.i. ${ }^{1}$ \\
\hline$[66]$ & Greenhouse gas emissions & $\mathrm{g} \mathrm{CO}_{2} \mathrm{ep} / \mathrm{kWh}$ \\
\hline$[66,68]$ & Land use & $\mathrm{m}^{2} / \mathrm{MWh}$ \\
\hline$[66,68]$ & Area requirements & $\mathrm{m}^{2} / \mathrm{kW}$ \\
\hline$[66]$ & Impacts on amenity & Qualitative \\
\hline$[66]$ & External cost (environmental) & $€ \mathrm{c} / \mathrm{kWh}$ \\
\hline$[66]$ & Water consumptions & $\mathrm{Kg} / \mathrm{kWh}$ \\
\hline [72] & Low-carbon energy solution & n.i. ${ }^{1}$ \\
\hline \multicolumn{3}{|l|}{ Political } \\
\hline$[65,68]$ & Integrated energy objectives & n.i. ${ }^{1}$ \\
\hline [65] & Coordinated energy planning institutions & n.i. 1 \\
\hline$[65]$ & Legitimate planning procedures & n.i. 1 \\
\hline$[65]$ & Statutory planning regulations & n.i. 1 \\
\hline [68] & Participative processes & n.i. ${ }^{1}$ \\
\hline \multicolumn{3}{|l|}{ Social } \\
\hline$[65,68]$ & Stakeholder involvement & n.i. ${ }^{1}$ \\
\hline$[66,68]$ & Social acceptability & Qualitative \\
\hline$[66,68,72]$ & Social impacts & Qualitative \\
\hline [66] & External cost (human health) & $€ \mathrm{c} / \mathrm{kWh}$ \\
\hline$[66,72]$ & Job creation & Job-years/GWh \\
\hline$[66]$ & External supply risk & n.i. ${ }^{1}$ \\
\hline$[66,68]$ & Visual disturbance & n.i. 1 \\
\hline$[68]$ & Expected cost-benefits & n.i. 1 \\
\hline$[72]$ & Energy justice & n.i. 1 \\
\hline [72] & Energy poverty & n.i. 1 \\
\hline [72] & Technical know-how & n.i. ${ }^{1}$ \\
\hline
\end{tabular}

\section{Discussion}

The principal goal of this work was to determine whether the SEP concept, considering it as a tool to carry out energy planning processes, is helping or could help to overcome barriers that have emerged in the integration of RE technologies into electric systems, which are related to aspects beyond the techno-economic ones. In this sense, there are a couple of differences from other literature reviews conducted in the field [7-9,11,29]. On one hand, our review thought of the SEP concept as a tool for planning and designing the integration of RE projects into electric systems, instead of for obtaining insights from existing RE systems. An exception to this is the review performed by Picchi et al. [29]. They discussed approaches and methods regarding landscape planning but focused on the relationship between RE and ecosystem services. On the other hand, our review considered aspects (as well as their corresponding criteria, factors, and indicators) other than the environmental, spatial, and landscape impacts included in the planning process related to RE technologies.

The systematic literature review carried out in this work revealed three main results that should be highlighted: (i) the SEP concept has featured in scientific literature for less than a decade; (ii) only one-third of the articles found considered aspects beyond the techno-economic ones; and (iii) just one of those articles used the SEP concept as a tool for an energy planning process. Other studies that have used the SEP concept and included aspects beyond the techno-economic ones were applied to identify criteria, factors, or indicators from previous energy planning processes and existing RE systems. In addition, three-quarters of the studies that used the SEP concept were applied at the local level. There are two main reasons for this. The first one is associated with the history of space and 
energy planning integration, which was mainly related to city physical-functional organization [39]. The second reason is seemingly directly related to the nature of RE sources. As those sources are essentially distributed, the options for energy strategies are highly shaped by local contexts [59]. In other words, when expanding the level of SEP implementation, details that are only appreciable at a local scale can be ignored, since it is possible to consider all of the conditioning factors that affect the SEP in greater detail.

Therefore, our results indicate that the manner in which the SEP concept can be used as a tool to carry out energy planning processes is still an open question. This knowledge gap could be addressed from different perspectives but would make more sense through a trans- or multi-disciplinary approach.

However, based on the research performed by Mostegl et al. [68], the SEP concept, when used as a strategic tool in energy planning processes which involve the local community, has the potential to provide significant insights into how to prevent and avoid environmental concerns in general and social conflict in particular, in the integration of RE into electric systems. This is aligned with what was pointed out by Oudes and Stremke [27]. Mostegl et al. [68] even claim that when using SEP approaches, those concerns and conflicts could be identified before the formal (or governmental) planning process and could reveal preferences associated with the promotion of RE solutions, possible household savings, and investment models. This could be addressed by public participation through questionnaires and choice experiments, which would include projecting tailor-made visualizations of RE technologies into the local landscape. Nevertheless, according to Thygesen and Agarwal [65], for an effective incorporation of these and other aspects and practices which could give multi-dimensional benefits, governments need to establish mandatory regulations.

A total of 24 criteria, factors, and indicators associated with aspects beyond the techno-economic ones were identified. Ten of these criteria, factors, and indicators are measurable and the rest could be assigned a measuring unit. In addition, they could be regrouped or re-classified into other aspects, such as socio-environmental, socio-economic, and cultural aspects, among others. The aspects identified and their respective criteria, factors, and indicators provide a benchmark to consider for future work in both the field of research and the current planning practices implemented by different policymakers and stakeholders. Therefore, on one hand, we suggest performing trans- and multi-disciplinary research in order to address gaps in the knowledge. On the other hand, due to the fact that most countries are using techno-economic approaches in their energy planning processes [16], we suggest that planners, governments, and investors incorporate aspects beyond techno-economic ones in their energy planning processes.

Furthermore, according to previous review works [9,29], the most controversial RE system in terms of direct landscape effects is wind, followed by solar PV. In terms of environmental impacts and effects on land use, bioenergy is the most discussed. Therefore, we suggest starting with special attention being placed on these technologies. In this sense, the work carried out by Mostegl et al. [68] is a concrete example of how the SEP concept, used as a strategy tool, can help to address and overcome conflict in the integration of wind energy and solar PV technologies into electric systems, in terms of the acceptability of RE planning in a given socio-political context. The authors of that work also claim that concerns and conflicts can be identified before the formal (or governmental) planning process when the SEP concept is used as a strategy tool. Furthermore, according to Frolova et al. [9] (p. 335), "If RE projects are properly located and designed and are beneficial for local people and tourists, society will gradually learn to love these landscapes and to adapt to their aesthetic properties."

A limitation of this work is related to the fact that other concepts of energy planning, such as sustainable energy planning, were not included. This was because, for example, in the literature on sustainable energy planning, it has mainly been associated with theoretical methods, models, and approaches in which planning and energy policies are still unintegrated with spatial planning. Sustainable energy planning is a concept focused on long-term scenarios for future energy systems, instead of analyses on the integration of RE technologies in the short-term. Other planning concepts suffer from similar issues. In any case, sustainable energy planning and other concepts could have 
provided stronger support for the aspects found beyond the techno-economic ones. However, based on the aspects and the criteria, factors, and indicators found through the SEP concept in this work, we believe that the insights gained would very likely have been similar. In any case, due to the high spatial dilution nature of RE sources, we argue that the SEP is an appropriate concept for addressing the energy planning process, when additional aspects beyond the techno-economic ones are considered and the local communities are involved in the process.

Finally, the results found in this paper could be useful for future works in the field; for example, for those studies that may include environmental and social aspects, or that involve local communities. It could also be useful for SEP processes that might implement governments at different levels. All of this could help to prevent barriers in the integration of high levels of RE technologies into electric systems. This could also serve to accelerate the energy transition.

\section{Conclusions}

The main objective of this work was to reveal whether the spatial energy planning (SEP) concept, considering it as a tool to carry out energy planning processes, is helping or could help to overcome challenges and barriers that have emerged in the integration of renewable energy (RE) technologies worldwide at different levels. These issues are directly related to aspects beyond the techno-economic ones, such as environmental, social, and other aspects.

Based on a systematic review of high-quality scientific literature, we concluded that, on one hand, how the SEP concept can be used as a strategic tool for carrying out energy planning processes is still an open question. On the other hand, the SEP concept seems to be an unexploited strategic tool with the potential to provide significant insight into energy planning processes that could prevent barriers to the integration of RE technologies at different scales and levels.

In other words, on one hand, more trans- and multi-disciplinary research on how to incorporate the SEP concept into energy planning processes is needed. Additionally, on the other hand, the application to current practices related to energy planning processes can be improved via the SEP concept as a strategic tool that involves the local community and considers additional aspects beyond the techno-economic ones. This is especially true because most of the tools and methods for modeling, design, and planning the integration of RE technologies into energy systems are mainly focused on techno-economic analyses, but also because they are theoretical approaches where planning and energy policies are still unintegrated with spatial planning.

Due to the large increases in the integration of RE technologies into the electric system that are being applied to address climate risks, the SEP concept as a strategic tool could help to overcome socio-environmental, socio-economic, and socio-cultural barriers. This would be useful for planners, governments, energy strategy policies, investors, and other societal decision-makers. Last but not least, it would be useful for accelerating the needed sustainable energy transition.

Author Contributions: Initial idea and research aim, J.C.O.-A. and E.M.-C.; data collection, J.C.O.-A.; formal analysis, all authors; writing-original draft preparation, J.C.O.-A. and M.F.; writing — review and editing, J.T.-C. and E.M.-C.; supervision, E.M.-C.; funding acquisition, M.F. All authors have read and agreed to the published version of the manuscript.

Funding: This paper was elaborated in the scope of the research carried out within the project "Adaptation to sustainable energy transition in Europe: Environmental, socio-economic and cultural aspects (ADAPTAS)" (Ministry of Economy, Industry and Competitiveness and State Research Agency of Spain, and European Regional Development Fund, CSO2017-86975-R).

Acknowledgments: This work was supported by the Campus Patagonia of the Universidad Austral de Chile and the Vice-Rectorate of Research of the University of Jaén through "Acción 4" grant: "Ayudas predoctorales para la Formación de Personal Investigador". The work was presented at the 5th Renewable Energy Sources-Research and Business (RESRB) conference held on 7-8 September 2020 in Brussels (Belgium).

Conflicts of Interest: The authors declare no conflict of interest. 


\section{References}

1. Jacobson, M.Z.; Delucchi, M.A.; Cameron, M.A.; Mathiesen, B. Matching demand with supply at low cost in 139 countries among 20 world regions with 100\% intermittent wind, water, and sunlight (WWS) for all purposes. Renew. Energy 2018, 123, 236-248. [CrossRef]

2. Bogdanov, D.; Farfan, J.; Sadovskaia, K.; Aghahosseini, A.; Child, M.; Gulagi, A.; Oyewo, A.S.; de Souza, L.; Simas, N.; Breyer, C. Radical transformation pathway towards sustainable electricity via evolutionary steps. Nat. Commun. 2019, 1-16. [CrossRef] [PubMed]

3. IRENA Global Renewables Outlook. Energy Transformation 2050; IRENA: Abu Dhabi, UAE, 2020.

4. REN21 Renewables 2020 Global Status Report; REN21: Paris, France, 2020.

5. Brown, T.W.; Bischof-Niemz, T.; Blok, K.; Breyer, C.; Lund, H.; Mathiesen, B.V. Response to 'Burden of proof: A comprehensive review of the feasibility of $100 \%$ renewable-electricity systems'. Renew. Sustain. Energy Rev. 2018, 92, 834-847. [CrossRef]

6. IRENA Renewable Power Generation Costs in 2019; IRENA: Abu Dhabi, UAE, 2019.

7. Trainor, A.M.; McDonald, R.I.; Fargione, J. Energy sprawl is the largest driver of land use change in United States. PLoS ONE 2016, 11, e0162269. [CrossRef] [PubMed]

8. Van Zalk, J.; Behrens, P. The spatial extent of renewable and non-renewable power generation: A review and meta-analysis of power densities and their application in the U.S. Energy Policy 2018, 123, 83-91. [CrossRef]

9. Frolova, M.; Centeri, C.; Benediktsson, K.; Hunzi Ker, M.; Kabai, R.; Scognamiglio, A.; Martinopoulos, G.; Sismani, G.; Brito, P.; Muñoz-Cerón, E.; et al. Effects of renewable energy on landscape in Europe: Comparison of hydro, wind, solar, bio-, geothermal and infrastructure energy landscapes. Hung. Geogr. Bull. 2019, 68, 317-339. [CrossRef]

10. Frolova, M.; Frantál, B.; Ferrario, V.; Centeri, C.; Herrero-Luque, D.; Grónás, V.; MartináT, S.; Puttilli, M.; Almeida, L.; D'angelo, F. Diverse energy transition patterns in Central and Southern Europe: A comparative study of institutional landscapes in the Czech Republic, Hungary, Italy, ans Spain. J. Landsc. Ecol. 2020, 17, 65-89.

11. Greer-Wootten, B. Energy landscape research - Lessons from Southern Europe? Morav. Geogr. Rep. 2017, 25, 60-72. [CrossRef]

12. Bouzarovski, S.; Pasqualetti, M.J.; Broto, V.C. The Routledge Research Companion to Energy Geographies; Taylor \& Francis: London, UK, 2017; ISBN 978-1-31704-357-7.

13. Roth, M.; Eiter, S.; Röhner, S.; Nruse, A.; Schmits, S.; Frantál, B.; Centeri, C.; Frolova, M.; Buchecker, M.; Stober, D.; et al. Renewable Energy and Landscape Quality; JOVIS: Berlin, Germany, 2018; ISBN 978-3-86859-524-6.

14. EEA Adaptation Challenges and Opportunities for the European Energy System: Building a Climate-Resilient Low-Carbon Energy System; European Environment Agency: Copenhagen, Denmark, 2019.

15. Frolova, M.; Prados, M.J.; Nadaï, A. Emerging renewable energy landscapes in southern European countries. In Renewable Energies and European Landscapes: Lessons from Southern European Cases; Springer: Cham, Switzerland, 2015; pp. 3-24. ISBN 978-9-40179-843-3.

16. IRENA. Planning for the Renewable Future: Long-Term Modelling and Tools to Expand Variable Renewable Power in Emerging Economies; International Renewable Energy Agency: Abu Dhabi, UAE, 2017.

17. Manoj Kumar, N.; Chopra, S.S.; Chand, A.A.; Elavarasan, R.M.; Shafiullah, G.M. Hybrid renewable energy microgrid for a residential community: A techno-economic and environmental perspective in the context of the SDG7. Sustainability 2020, 12, 3944. [CrossRef]

18. Manoj Kumar, N.; Ghosh, A.; Chopra, S.S. Power Resilience Enhancement of a Residential Electricity User Using Photovoltaics and a Battery Energy Storage System under Uncertainty Conditions. Energies 2020, 13, 4193. [CrossRef]

19. Burgess, P.J.; Rivas Casado, M.; Gavu, J.; Mead, A.; Cockerill, T.; Lord, R.; van der Horst, D.; Howard, D.C. A framework for reviewing the trade-offs between, renewable energy, food, feed and wood production at a local level. Renew. Sustain. Energy Rev. 2012, 16, 129-142. [CrossRef]

20. Stremke, S.; van den Dobbelsteen, A. Sustainable Energy Landscapes: Designing, Planning, and Development; CRC: Boca Raton, FL, USA, 2013; ISBN 9781439894040.

21. Hansen, K.; Breyer, C.; Lund, H. Status and perspectives on 100\% renewable energy systems. Energy 2019, 175, 471-480. [CrossRef] 
22. Weinand, J.M.; McKenna, R.; Fichtner, W. Developing a municipality typology for modelling decentralised energy systems. Util. Policy 2019, 57, 75-96. [CrossRef]

23. Balest, J.; Secco, L.; Pisani, E.; Garegnani, G. Municipal transitions: The social, energy, and spatial dynamics of sociotechnical change in South Tyrol, Italy. Energy Res. Soc. Sci. 2019, 54, 211-223. [CrossRef]

24. Lammers, I.; Hoppe, T. Analysing the institutional setting of local renewable energy planning and implementation in the EU: A systematic literature review. Sustainability 2018, 10, 3212. [CrossRef]

25. Qudrat-Ullah, H.; Akrofi, M.M.C.; Kayal, A. Analyzing actors' engagement in sustainable energy planning at the local level in Ghana: An empirical study. Energies 2020, 13, 2028. [CrossRef]

26. Abart-Heriszt, L.; Erker, S.; Stoeglehner, G. The energy mosaic Austria-A nationwide energy and greenhouse gas inventory on municipal level as action field of integrated spatial and energy planning. Energies 2019, 12, 3065. [CrossRef]

27. Oudes, D.; Stremke, S. Spatial transition analysis: Spatially explicit and evidence-based targets for sustainable energy transition at the local and regional scale. Landsc. Urban Plan. 2018, 169, 1-11. [CrossRef]

28. Terrados, J.; Almonacid, G.; Pérez-Higueras, P. Proposal for a combined methodology for renewable energy planning. Application to a Spanish region. Renew. Sustain. Energy Rev. 2009, 13, 2022-2030. [CrossRef]

29. Picchi, P.; van Lierop, M.; Geneletti, D.; Stremke, S. Advancing the relationship between renewable energy and ecosystem services for landscape planning and design: A literature review. Ecosyst. Serv. 2019, 35, 241-259. [CrossRef]

30. Dominkovic, D.F.; Stark, G.; Hodge, B.M.; Pedersen, A.S. Integrated energy planning with a high share of variable renewable energy sources for a Caribbean Island. Energies 2018, 11, 2193. [CrossRef]

31. Liu, R.; Sun, H.; Zhang, L.; Zhuang, Q.; Zhang, L.; Zhang, X.; Chen, Y. Low-carbon energy planning: A hybrid MCDM method combining DANP and VIKOR approach. Energies 2018, 11, 3401. [CrossRef]

32. Maçaira, P.M.; Cyrillo, Y.M.; Oliveira, F.L.C.; Souza, R.C. Including wind power generation in Brazil's long-term optimization model for energy planning. Energies 2019, 12, 826. [CrossRef]

33. Mirjat, N.H.; Uqaili, M.A.; Harijan, K.; Mustafa, M.W.; Rahman, M.M.; Khan, M.W.A. Multi-criteria analysis of electricity generation scenarios for sustainable energy planning in Pakistan. Energies 2018, 11, 757. [CrossRef]

34. Mroue, A.M.; Mohtar, R.H.; Pistikopoulos, E.N.; Holtzapple, M.T. Energy Portfolio Assessment Tool (EPAT): Sustainable energy planning using the WEF nexus approach-Texas case. Sci. Total Environ. 2019, 648, 1649-1664. [CrossRef]

35. Solangi, Y.A.; Tan, Q.; Mirjat, N.H.; Ali, S. Evaluating the strategies for sustainable energy planning in Pakistan: An integrated SWOT-AHP and Fuzzy-TOPSIS approach. J. Clean. Prod. 2019, 236, 117655. [CrossRef]

36. Nsafon, B.E.K.; Butu, H.M.; Owolabi, A.B.; Roh, J.W.; Suh, D.; Huh, J.S. Integrating multi-criteria analysis with PDCA cycle for sustainable energy planning in Africa: Application to hybrid mini-grid system in Cameroon. Sustain. Energy Technol. Assess. 2020, 37, 100628. [CrossRef]

37. Bamisile, O.; Huang, Q.; Xu, X.; Hu, W.; Liu, W.; Liu, Z.; Chen, Z. An approach for sustainable energy planning towards $100 \%$ electrification of Nigeria by 2030. Energy 2020, 197, 117172. [CrossRef]

38. Riaz, M.; Salabun, W.; Farid, H.M.A.; Ali, N.; Watróbski, J. A robust q-rung orthopair fuzzy information aggregation using einstein operations with application to sustainable energy planning decision management. Energies 2020, 13, 2155. [CrossRef]

39. de Pascali, P.; Bagaini, A. Energy transition and urban planning for local development. A critical review of the evolution of integrated spatial and energy planning. Energies 2019, 12, 35. [CrossRef]

40. Knowles, R. Energy and Form: An Ecological Approach to Urban Growth; MIT Press: Cambridge, MA, USA, 1974; ISBN 0262610256.

41. Altshuler, A. Review of the Costs of Sprawl. J. Am. Plan. Assoc. 1977, 45, 202-209.

42. Owens, S.E. Energy, Planning and Urban Form; Taylor \& Francis: London, UK, 1986; ISBN 0850861187.

43. Owens, S.E. Land-use planning for energy efficiency. Appl. Energy 1992, 43, 81-114. [CrossRef]

44. Breheny, M. The compact city and transport energy consumption. Trans. Inst. Br. Geogr. 1995, $20,81-101$. [CrossRef]

45. Givoni, B. Climate Considerations in Building and Urban Design; John Wiley \& Son: New York, NY, USA, 1998; ISBN 978-0-471-29177-0.

46. Ratti, C.; Baker, N.; Steemers, K. Energy consumption and urban texture. Energy Build. 2005, 37, 762-776. [CrossRef] 
47. Mirakyan, A.; de Guio, R. Integrated energy planning in cities and territories: A review of methods and tools. Renew. Sustain. Energy Rev. 2013, 22, 289-297. [CrossRef]

48. Pohekar, S.D.; Ramachandran, M. Application of multi-criteria decision making to sustainable energy planning-A review. Renew. Sustain. Energy Rev. 2004, 8, 365-381. [CrossRef]

49. Nijkamp, P.; Volwahsen, A. New directions in integrated regional energy planning. Energy Policy 1990, 18, 764-773. [CrossRef]

50. Tsoutsos, T.; Drandaki, M.; Frantzeskaki, N.; Iosifidis, E.; Kiosses, I. Sustainable energy planning by using multi-criteria analysis application in the island of Crete. Energy Policy 2009, 37, 1587-1600. [CrossRef]

51. Koo, J.; Han, K.; Yoon, E.S. Integration of CCS, emissions trading and volatilities of fuel prices into sustainable energy planning, and its robust optimization. Renew. Sustain. Energy Rev. 2011, 15, 665-672. [CrossRef]

52. Quijano, H.R.; Botero, B.S.; Domínguez, B.J. MODERGIS application: Integrated simulation platform to promote and develop renewable sustainable energy plans, Colombian case study. Renew. Sustain. Energy Rev. 2012, 16, 5176-5187. [CrossRef]

53. Saranti, A.; Tsoutsos, T.; Mandalaki, M. Sustainable Energy Planning. Design Shading Devices with Integrated Photovoltaic Systems for Residential Housing Units. Procedia Eng. 2015, 123, 479-487. [CrossRef]

54. Montajabiha, M. An Extended PROMETHE II Multi-Criteria Group Decision Making Technique Based on Intuitionistic Fuzzy Logic for Sustainable Energy Planning. Group Decis. Negot. 2016, 25, 221-244. [CrossRef]

55. Al-Qudaimi, A.; Kumar, A. Sustainable energy planning decision using the intuitionistic fuzzy analytic hierarchy process: Choosing energy technology in Malaysia: Necessary modifications. Int. J. Sustain. Energy 2018, 37, 436-437. [CrossRef]

56. Neshat, N.; Hadian, H.; Rahimi Alangi, S. Technological learning modelling towards sustainable energy planning. J. Eng. Des. Technol. 2020, 18, 84-101. [CrossRef]

57. Haidar, A.M.A.; Fakhar, A.; Helwig, A. Sustainable energy planning for cost minimization of autonomous hybrid microgrid using combined multi-objective optimization algorithm. Sustain. Cities Soc. 2020, 62, 102391. [CrossRef]

58. Cormio, C.; Dicorato, M.; Minoia, A.; Trovato, M. A regional energy planning methodology including renewable energy sources and environmental constraints. Renew. Sustain. Energy Rev. 2003, 7, 99-130. [CrossRef]

59. Stoeglehner, G. Integrated spatial and energy planning: A means to reach sustainable development goals. Evol. Inst. Econ. Rev. 2020, 17, 473-486. [CrossRef]

60. Stoeglehner, G.; Narodoslawsky, M.; Erker, S.; Neugebauer, G. Introduction. In SpringerBriefs in Applied Sciences and Technology; Springer: Cham, Switzerland, 2016; pp. 1-10.

61. Stoeglehner, G.; Narodoslawsky, M.; Erker, S.; Neugebauer, G. System interrelations between spatial structures, energy demand, and energy supply. In SpringerBriefs in Applied Sciences and Technology; Springer: Cham, Switzerland, 2016; pp. 11-34.

62. Moher, D.; Liberati, A.; Tetzlaff, J.; Altman, D.G.; Altman, D.; Antes, G.; Atkins, D.; Barbour, V.; Barrowman, N.; Berlin, J.A.; et al. Preferred reporting items for systematic reviews and meta-analyses: The PRISMA statement. PLoS Med. 2009, 6, e1000097. [CrossRef]

63. Reiter, D. Optimising regional energy systems: Spatial energy planning in salzburg focusing on heat supply. Euroheat Power (Engl. Ed.) 2013, 10, 20-24.

64. Schubert, S. The Need for Local Thermal Energy Planning. J. Urban Technol. 2014, 21, 21-36. [CrossRef]

65. Thygesen, J.; Agarwal, A. Key criteria for sustainable wind energy planning-Lessons from an institutional perspective on the impact assessment literature. Renew. Sustain. Energy Rev. 2014, 39, 1012-1023. [CrossRef]

66. Scognamiglio, A. "Photovoltaic landscapes": Design and assessment. A critical review for a new transdisciplinary design vision. Renew. Sustain. Energy Rev. 2016, 55, 629-661. [CrossRef]

67. Choi, G.B.; Lee, S.G.; Lee, J.M. Multi-period energy planning model under uncertainty in market prices and demands of energy resources: A case study of Korea power system. Chem. Eng. Res. Des. 2016, 114, 341-358. [CrossRef]

68. Mostegl, N.M.; Pröbstl-Haider, U.; Haider, W. Spatial energy planning in Germany: Between high ambitions and communal hesitations. Landsc. Urban Plan. 2017, 167, 451-462. [CrossRef]

69. Garegnani, G.; Sacchelli, S.; Balest, J.; Zambelli, P. GIS-based approach for assessing the energy potential and the financial feasibility of run-off-river hydro-power in Alpine valleys. Appl. Energy 2018, 216, 709-723. [CrossRef] 
70. Böttcher, F.; Casasso, A.; Götzl, G.; Zosseder, K. TAP-Thermal aquifer Potential: A quantitative method to assess the spatial potential for the thermal use of groundwater. Renew. Energy 2019, 142, 85-95. [CrossRef]

71. Epting, J.; Böttcher, F.; Mueller, M.H.; García-Gil, A.; Zosseder, K.; Huggenberger, P. City-scale solutions for the energy use of shallow urban subsurface resources-Bridging the gap between theoretical and technical potentials. Renew. Energy 2020, 147, 751-763. [CrossRef]

72. Boamah, F. Desirable or debatable? Putting Africa's decentralised solar energy futures in context. Energy Res. Soc. Sci. 2020, 62, 101390. [CrossRef]

73. Lukač, N.; Špelič, D.; Štumberger, G.; Žalik, B. Optimisation for large-scale photovoltaic arrays' placement based on Light Detection and Ranging data. Appl. Energy 2020, 263, 114592. [CrossRef]

74. Gusatu, Y.; Zuidema, F. A Spatial Analysis of the Potentials for Offshore Wind Farm Locations in the North Sea Region: Challenges and Opportunities. ISPRS Int. J. Geo-Inf. 2020, 9, 96. [CrossRef]

Publisher's Note: MDPI stays neutral with regard to jurisdictional claims in published maps and institutional affiliations.

(C) 2020 by the authors. Licensee MDPI, Basel, Switzerland. This article is an open access article distributed under the terms and conditions of the Creative Commons Attribution (CC BY) license (http://creativecommons.org/licenses/by/4.0/). 